\title{
Endovascular treatment of complex aortic aneurysms: prevalence of acute kidney injury and effect on long-term renal function
}

\author{
Anna M. Sailer ${ }^{1,2}$ • Patricia J. Nelemans ${ }^{3}$ - Camille van Berlo ${ }^{1}$ - Ozan Yazar $^{4}$. \\ Michiel W. de Haan ${ }^{1}$ • Dominik Fleischmann ${ }^{2}$ - Geert Willem H. Schurink ${ }^{5}$
}

Received: 14 June 2015 /Revised: 26 August 2015 / Accepted: 31 August 2015 / Published online: 2 October 2015

(C) The Author(s) 2015. This article is published with open access at Springerlink.com

\begin{abstract}
Objectives To analyse predictors for short- and long-term renal function changes after fenestrated and branched endovascular aortic repair (EVAR).

Methods A total of 157 patients underwent fenestrated and branched EVAR. Procedural intra-arterial iodinated contrast volume was documented. Serum creatinine and estimated glomerular filtration rate (eGFR) at baseline, during $48 \mathrm{~h}$ following EVAR, at discharge and latest moment of follow-up were recorded. Development of post-EVAR acute kidney injury (AKI; according to AKIN criteria), and potential risk factors for renal failure were recorded. Multivariate regression analyses were used to identify independent risk factors for AKI and eGFR decrease during follow-up.

Results Forty-three patients (28\%) developed post-EVAR AKI. Long procedure time and occlusion of accessory renal arteries were independent risk factors for development of AKI. (odds ratio (OR) 1.005 per minute, $95 \%$ CI 1.001$1.01 ; p=0.025$ and OR 3.02, $95 \%$ CI 1.19-8.16; $p=0.029$ ).
\end{abstract}

Anna M. Sailer

karmanna@stanford.edu

1 Department of Radiology, Maastricht University Medical Centre, Maastricht, The Netherlands

2 Department of Radiology, Stanford University Hospitals and Clinics, Stanford, CA, USA

3 Department of Epidemiology, Maastricht University Medical Centre, Maatsricht, The Netherlands

4 Department of Vascular Surgery, Cliniques del Europe, Brussels, Belgium

5 Department of Surgery, Maastricht University Medical Centre, Maastricht, The Netherlands
Post-EVAR AKI was associated with a significantly increased risk for eGFR decrease at discharge and latest follow-up (hazard ratio (HR) 3.47, $95 \%$ CI 1.63-7.36, $p=0.001$ and HR $3.01,95 \%$ CI $1.56-5.80 ; p=0.001)$. Iodinated contrast volume was not an independent risk factor for AKI or eGFR decrease during follow-up.

Conclusion Development of post-EVAR AKI is an independent risk factor for long-term renal function decrease.

Key Points

- Longer procedure time is associated with an increased risk for AKI.

- Renal perfusion defects on angiography are associated with increased risk for AKI.

- Post-EVAR AKI is associated with higher probability for long-term eGFR decrease.

- Iodinated contrast volume is not an independent risk factor for AKI.

- Iodinated contrast volume is not an independent risk factor for long-term eGFR decrease.

Keywords Acute kidney injury · Endovascular procedures . Contrast media $\cdot$ Glomerular filtration rate $\cdot$ Aortic aneurysm

\section{Introduction}

Advantages in perioperative survival have led endovascular aortic repair (EVAR) to become first-line treatment for anatomically suitable aneurysms and complicated acute type B aortic dissections $[1,2]$. Developments in aortic stent grafts expanded the field of endovascular therapy towards thoracoabdominal aneurysms and chronic dissections with insufficient fixation zone $[3,4]$. In order to provide adequate graft sealing and, at the same time, preserving aortic side branch patency, the main renal arteries, celiac trunk, superior 
mesenteric artery and/or supra-aortic vessel are catheterized and stented via fenestrations or branches in the aortic main device. Over the last few years, fenestrated and branched EVAR procedures have increasingly been performed. Ongoing innovations in devices provide endovascular solutions for more and more challenging anatomy and pathology. The worldwide demographic shift and decreasing indications for open (surgical) aortic repair further contribute to this development. With endovascular procedure complexity, the amount of intra-arterial administered iodinated contrast media increases substantially. At the same time, new techniques like fusion image road-mapping and robotic navigation have been applied and are under further development to reduce procedural iodinated contrast volume and accelerate complex EVAR procedures $[5,6]$. For proper risk analysis and adequate procedure management, knowledge of predictors of renal function following complex EVAR is required. Despite numerous research in the field of iodinated contrast, the effect of currently used low-osmolar intra-arterial applied iodinated contrast on short-term and long-term renal function decrease remains unclear [7]. Several studies on renal outcome after endovascular aortic repair have been published, but these studies lack adjustments for contrast volume and other factors by a multivariate risk factor analysis for renal outcome [8-10].

The aim of this study was to evaluate predictors for shortand long-term renal function changes after complex fenestrated and branched endovascular aortic repair, with particular focus on risk factors for AKI and the effect of AKI on long term-renal damage.

\section{Materials and methods}

This retrospective study was approved by the institutional review board; written informed consent was waived. Serum creatinine ( $\mathrm{SCr}$ ) levels and estimated glomerular filtration rate (eGFR) changes were retrospectively evaluated in 157 consecutive patients who underwent fenestrated and/or branched endovascular aortic repair for juxta-, suprarenal and thoracoabdominal aortic aneurysms between January 2006 and March 2014 at our institution. All procedures were performed under general anaesthesia. Procedural intra-arterial iodinated contrast volume (iaIC, low-osmolar, $300 \mathrm{mg}$ iodine/ $\mathrm{ml}$ ) and procedure time were documented. SCr levels at baseline, during $48 \mathrm{~h}$ following the intervention, at discharge as well as during follow-up were retrieved from the electronic medical patient records. Corresponding eGFR levels were calculated using the Modification of Diet in Renal Disease formula [11]. Patient characteristics, including age, sex, presence of diabetes and congestive heart failure, were retrieved from the medical records. Procedure-related death was recorded. Procedure-related loss of renal parenchyma was assessed by reviewing procedural angiograms together with pre- and post- procedure CT: angiographically apparent perfusion defects by intentional stent graft coverage of accessory renal arteries as well as iatrogenic renal artery injuries with occlusion of renal artery branches during the EVAR procedures were recorded. Furthermore it was assessed whether the patients received additional iodinated contrast media during computed tomography angiography (CTA) within $48 \mathrm{~h}$ following the EVAR procedure.

\section{Assessment of post-EVAR acute kidney injury (AKI)}

Post-EVAR AKI was defined by comparing the individual post-EVAR SCr measurements to preoperative baseline $\mathrm{SCr}$ measurements. According to the definition of the Acute Kidney Injury Network criteria of AKI, patients with (1) an absolute $\mathrm{SCr}$ increase of at least $0.3 \mathrm{mg} / \mathrm{dl}$ and/or (2) a relative increase of at least $50 \%$ above baseline within $48 \mathrm{~h}$ following the complex EVAR procedures qualified to have post-EVAR AKI [12].

\section{Decrease in eGFR during follow-up}

The primary endpoint was decrease in eGFR at discharge. At baseline, discharge and latest moment of follow-up patients were grouped according to their eGFR into five categories: (1) eGFR $<15 \mathrm{ml} / \mathrm{min} / 1.73 \mathrm{~m}^{2}$, (2) eGFR $15-29 \mathrm{ml} / \mathrm{min} / 1.73 \mathrm{~m}^{2}$, (3) eGFR $30-44 \mathrm{ml} / \mathrm{min} / 1.73 \mathrm{~m}^{2}$, (4) eGFR $45-59 \mathrm{ml} / \mathrm{min} /$ $1.73 \mathrm{~m}^{2}$ and (5) eGFR $\geq 60 \mathrm{ml} / \mathrm{min} / 1.73 \mathrm{~m}^{2}$. Decrease in eGFR was defined as a transition to a category with lower eGFR when compared to baseline. Secondary endpoint was decrease in eGFR at latest moment of follow-up.

\section{Statistical analysis}

For descriptive purposes, categorical variables were presented as absolute numbers and percentages. Continuous variables were presented as a mean \pm standard deviations (if normally distributed) or as a median with a range (if not normally distributed). For development of AKI, the effects of risk factors were analysed using multivariate logistic regression. For eGFR decrease at discharge of last follow-up, data were analysed with time-to-event analysis to account for differences in follow-up between patients. Multivariable Cox regression analyses were used for calculation of hazard ratios with corresponding $95 \%$ confidence intervals. The hazard ratios represent the independent effect of predefined risk factors on the probability of an event. Observations were censored at occurrence of an event (eGFR decrease) or at the end of follow-up. Patients with transient eGFR decrease, with eGFR decrease by one category at discharge but recovery to the eGFR category at baseline, were considered as event-free at the end of follow-up. Predefined risk factors considered relevant as potential predictors were age, sex, baseline eGFR, 
administered contrast volume, presence or absence of AKI, additional administration of iodinated contrast within $48 \mathrm{~h}$ post EVAR, renal artery branch occlusion, diabetes and congestive heart failure. $P$ values less than 0.05 were considered to indicate statistical significance. Analyses were performed with SPSS statistics 20.0, Chicago, Illinois.

\section{Results}

The study group consisted of 131 men and 26 women with a mean age of $73 \pm 6$ years. The distribution of baseline characteristics is presented in Table 1. Median stay until discharge was 6 days (range 2-61 days, interquartile range (IQR) 3-9) and median time until last follow-up was 380 days (range 162762 days, IQR 117-925). One patient died perioperatively and this patient was excluded from the analysis because no data were accessible for post-EVAR renal function. Another nine patients died within 30 days (range 3-28 days) after the intervention as a result of procedure-related complications. Seven of those nine patients (78 \%) developed post-EVAR AKI. Among the other 146 patients, 36 patients (24\%) developed post-EVAR AKI. In total, 43 of 156 patients $(28 \%)$ developed post-EVAR AKI. Mean procedural iaIC volume was $162 \pm 77 \mathrm{ml}$ (range $50-450 \mathrm{ml}$ ). Mean procedural iaIC volume in patients who developed post-EVAR AKI was 195 $\pm 88 \mathrm{ml}$ (range 50-350 ml) versus $149 \pm 69 \mathrm{ml}$ (range 65$450 \mathrm{ml})$ in patients without post-EVAR AKI $(p=0.001)$. Mean procedure time in patients who developed post-EVAR AKI was 282 $\pm 138 \mathrm{~min}$ (range 119-603 $\mathrm{min}$ ) versus $197 \pm 89 \mathrm{~min}$ (range 69-395 $\mathrm{min}$ ) in patients without post-EVAR AKI ( $p=$ $0.001)$. In 26 patients (17\%), procedure-related loss of renal parenchyma was apparent.

The results of the logistic regression analysis evaluating the independent contribution of factors for the development of post-EVAR AKI are shown in Table 2. Development of AKI was significantly associated with procedure time (odds ratio (OR) per minute $1.005,95 \%$ CI 1.001-1.01, $p=0.001$ ) and renal artery branch occlusion (OR 3.02, $95 \%$ CI 1.12-8.16, $p=0.029$ ). Although iodinated contrast volume was significantly higher in patients with AKI in the univariate analysis (Table 1), iodinated contrast volume was no longer an independent risk factor for post-EVAR AKI after adjustment for other factors in the multivariate analysis.

Table 3 shows the results from the Cox proportional hazard model to assess the independent effects of predefined risk factors on probability of eGFR decrease at discharge. At discharge, the number of patients with eGFR decrease by at least one category was 37 . Development of post-EVAR AKI was associated with a significantly increased risk for eGFR decrease at discharge (hazard ratio (HR) 3.47, 95 \% CI 1.63 $7.36 ; p=0.001)$. Non-significantly but slightly increased hazard ratios were observed for accessory renal artery occlusion, iodinated contrast volume, age, male gender and patients with diabetes $(p>0.05)$.

Table 4 shows the results for long-term eGFR decrease. At the moment of last follow-up, the number of patients with eGFR decrease by at least one category was 51 . Patients with

Table 1 Baseline characteristics of the entire patient population $(n=157)$ and distribution between patients with $(n=43)$ and without AKI $(n=113)$

\begin{tabular}{|c|c|c|c|c|c|c|c|c|c|c|c|c|c|c|}
\hline & \multicolumn{7}{|c|}{ All patients } & \multicolumn{3}{|l|}{ AKI } & \multicolumn{3}{|c|}{ No AKI } & \multirow[b]{2}{*}{$\begin{array}{l}P \\
\text { value }\end{array}$} \\
\hline & Mean & $\begin{array}{l}\text { Std. } \\
\text { deviation }\end{array}$ & Median & $25 p$ & $75 p$ & Yes & No & Mean & $\begin{array}{l}\text { Std. } \\
\text { deviation }\end{array}$ & Yes & Mean & $\begin{array}{l}\text { Std. } \\
\text { deviation }\end{array}$ & Yes & \\
\hline Age (years) & 73 & 6 & 73 & 68 & 77 & & & 72 & 6 & & 73 & 6 & & 0.801 \\
\hline Baseline eGFR (ml/min/1.73 $\left.\mathrm{m}^{2}\right)$ & 63 & 18 & 63 & 49 & 78 & & & 64 & 18 & & 61 & 19 & & 0.263 \\
\hline Baseline serum creatinine $(\mu \mathrm{mol} / \mathrm{l})$ & 106 & 37 & 97 & 84 & 119 & & & 104 & 36 & & 110 & 38 & & 0.116 \\
\hline Intra-arterial contrast volume $(\mathrm{ml})$ & 162 & 77 & 150 & 100 & 200 & & & 149 & 69 & & 195 & 88 & & 0.001 \\
\hline Procedure time (min) & 220 & 110 & 196 & 140 & 276 & & & 282 & 138 & & 197 & 89 & & 0.001 \\
\hline BMI $\left(\mathrm{kg} / \mathrm{m}^{2}\right)$ & 26 & 4 & 26 & 24 & 28 & & & 26 & 4 & & 26 & 4 & & 0.710 \\
\hline Male gender $(n)$ & & & & & & 131 & 26 & & & $79 \%$ & & & $86 \%$ & 0.303 \\
\hline Congestive heart failure $(n)$ & & & & & & 15 & 142 & & & $12 \%$ & & & $9 \%$ & 0.599 \\
\hline Hypertension $(n)$ & & & & & & 82 & 75 & & & $56 \%$ & & & $51 \%$ & 0.616 \\
\hline Hyperlipidaemia $(n)$ & & & & & & 109 & 48 & & & $72 \%$ & & & $69 \%$ & 0.846 \\
\hline Diabetes $(n)$ & & & & & & 13 & 144 & & & $9 \%$ & & & $8 \%$ & 0.787 \\
\hline $\begin{array}{l}\text { CT angiography within } 48 \mathrm{~h} \text { post EVAR } \\
\quad(n)\end{array}$ & & & & & & 51 & 106 & & & $21 \%$ & & & $18 \%$ & 0.731 \\
\hline $\begin{array}{l}\text { Accessory renal artery coverage/renal } \\
\text { artery branch occlusion, with perfu- } \\
\text { sion defect }(n)\end{array}$ & & & & & & 26 & 131 & & & $31 \%$ & & & $14 \%$ & 0.02 \\
\hline
\end{tabular}

$25 p$ 25th percentile, $75 p 75$ th percentile 
Table 2 Logistic regression analysis for various risk factors for AKI within $48 \mathrm{~h}$ after complex EVAR

\begin{tabular}{llll}
\hline & Odds ratio & $95 \%$ CI & $P$ value \\
\hline Age (per life-year) & 1.04 & $0.960-1.127$ & 0.334 \\
Sex & 1.357 & $0.415-4.432$ & 0.613 \\
Diabetes & 1.674 & $0.425-6.599$ & 0.426 \\
Congestive heart failure & 1.51 & $0.364-6.270$ & 0.571 \\
Baseline eGFR (per ml/min/1.73 m²) & 0.993 & $0.969-1.018$ & 0.605 \\
Iodinated contrast volume (per ml) & 1.003 & $0.997-1.009$ & 0.323 \\
CTA within $48 \mathrm{~h}$ post EVAR & 1.514 & $0.532-4.310$ & 0.437 \\
Renal artery occlusion & 3.021 & $1.118-8.163$ & 0.029 \\
Procedure time (min) & 1.005 & $1.001-1.010$ & 0.025 \\
\hline
\end{tabular}

post-EVAR AKI had a significantly increased probability of eGFR decrease at last follow-up (HR 3.01, 95 \% CI 1.56$5.80, p=0.001)$. Procedure time, iodinated contrast volume and other patient characteristics were not significantly associated with long-term eGFR decrease.

Figure 1 shows the distribution of eGFR categories in all patients over time. Figure 2 illustrates the mean eGFR measurements over time, for subgroups with and without AKI and renal artery occlusions, respectively. Both groups start at similar baseline mean eGFR. For patients with AKI, eGFR levels decrease sharply during $48 \mathrm{~h}$ following complex EVAR and show substantial recovery at discharge. At the end of followup eGFR levels are substantially lower than at baseline for patients who developed AKI, whereas patients without AKI show only minor decrease in mean eGFR levels at the end of follow-up when compared with baseline.

\section{Discussion}

This study presents a retrospective evaluation of renal function changes after intra-arterial administration of high volumes of low-osmolar iodinated contrast media in a large patient population. Well-documented pre- and post-interventional renal function testing and thorough follow-up allowed us to evaluate the renal function in the postoperative period as well as beyond discharge of the patients. In multivariate regression analyses, several risk factors were evaluated regarding their association with postoperative renal function decrease. We discuss the most important findings with respect to the design of the study and current literature.

\section{Influence of intra-arterial iodinated contrast and procedure time on short- and long-term renal function}

For postoperative renal function decrease, which we term 'post-EVAR AKI' throughout the manuscript, we used the definition from the Acute Kidney Injury Network (AKIN) to assess post-EVAR AKI in order to provide a commonly used definition of AKI in research and clinical practice [13-16]. Another definition of contrast material-induced nephropathy (CIN) uses SCr increase of at least $0.5 \mathrm{mg} / \mathrm{dl}$ and/or at least $25 \%$ above baseline within $72 \mathrm{~h}$ post intervention $[17,18]$. When applying the CIN criteria for AKI, the patient group who developed post-EVAR AKI would have been the same in our study, excluding two patients that were not included when applying the AKIN criteria. AKIN criteria were used in our study for two main reasons: (1) we followed a recently
Table 3 Cox regression analysis for various risk factors for eGFR decrease by at least one category at time of hospital discharge after complex EVAR

\begin{tabular}{llll}
\hline & Hazard ratio & $95 \%$ CI & $P$ value \\
\hline Age (per life-year) & 1.012 & $0.945-1.083$ & 0.74 \\
Sex & 1.169 & $0.423-3.233$ & 0.763 \\
Diabetes & 1.938 & $0.679-5.529$ & 0.216 \\
Congestive heart failure & 0.935 & $0.265-3.306$ & 0.917 \\
Baseline eGFR (per ml/min/1.73 m²) & 0.996 & $0.977-1.016$ & 0.722 \\
Iodinated contrast volume (per $\mathrm{ml})$ & 1.002 & $0.996-1.008$ & 0.58 \\
CTA within 48 h post EVAR & 1.216 & $0.506-2.219$ & 0.662 \\
Renal artery occlusion & 1.97 & $0.866-4.481$ & 0.106 \\
Acute kidney injury & 3.467 & $1.633-7.360$ & 0.001 \\
Procedure time (min) & 0.997 & $0.993-1.002$ & 0.204 \\
\hline
\end{tabular}


Table 4 Cox regression analysis for various risk factors for eGFR decrease by at least one category at latest moment of follow-up after complex EVAR

\begin{tabular}{llll}
\hline & Hazard ratio & $95 \% \mathrm{CI}$ & $P$ value \\
\hline Age (per life-year) & 1.02 & $0.964-1.079$ & 0.5 \\
Sex & 0.858 & $0.393-1.872$ & 0.7 \\
Diabetes & 1.113 & $0.372-3.327$ & 0.56 \\
Congestive heart failure & 0.431 & $0.119-1.562$ & 0.23 \\
Baseline eGFR (per ml/min $/ 1.73 \mathrm{~m}^{2}$ ) & 0.995 & $0.978-1.013$ & 0.616 \\
Iodinated contrast volume $($ per $\mathrm{ml})$ & 1 & $0.996-1.005$ & 0.868 \\
CTA within 48 h post EVAR & 1.125 & $0.527-2.402$ & 0.761 \\
Renal artery occlusion & 1.371 & $0.774-2.790$ & 0.384 \\
Acute kidney injury & 3.013 & $1.563-5.808$ & 0.001 \\
Procedure time (min) & 1.001 & $0.997-1.004$ & 0.707 \\
\hline
\end{tabular}

advocated recommendation from the American College of Radiology in order to standardize the various used definitions of CIN [19] and (2) post-EVAR AKI might not be due to contrast medium but might predominantly be influenced by other factors rather than low-osmolar contrast volume [7]. With respect to the long-lasting discussion on the toxicity of iodinated contrast material [7, 20, 21], we made two observations: First iodinated contrast volume was associated with a slightly increased risk for every millilitre of contrast applied; however, it was not an independent risk factor for AKI and long-term renal function decrease post EVAR in complex aneurysms. Although univariate analysis suggested a significant effect of contrast volume for the development of AKI, this effect disappeared after adjustment for procedure time. This finding corroborates the hypothesis that high contrast volume is a marker for complexity of the procedure and that patients undergoing more complex procedures have higher risk for renal function decrease. One has to be aware that in any retrospective study, observed associations are not to be confused with causative relationships. Although we found a strong association between procedure time and short-term renal function decrease, a causal relationship for procedure time itself is hereby not proven. Second, it has been questioned whether post-interventional decrease in renal function is more likely a transient subclinical $[22,23]$ or even artificial $[24,25]$ short-

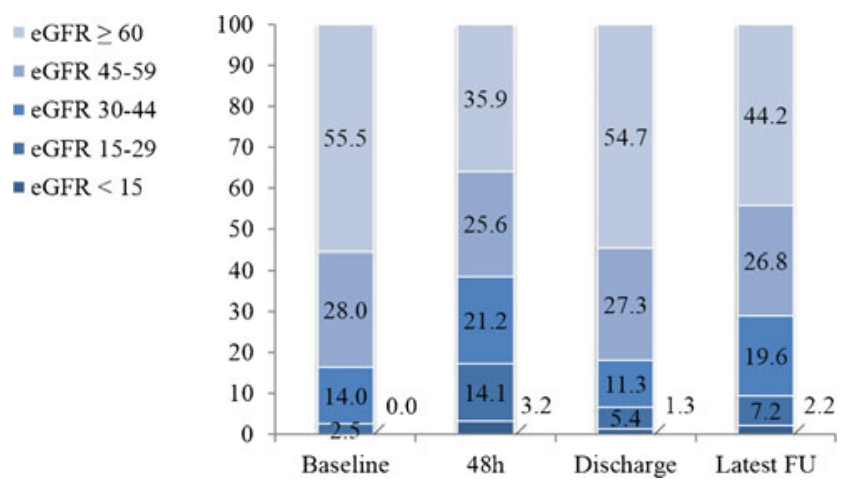

Fig. 1 Percentage of patients per eGFR category at baseline, during $48 \mathrm{~h}$ following EVAR, at discharge and latest follow-up (FU) term phenomenon, or indeed a relevant predictor for longterm renal dysfunction. When looking at the mid- and longterm renal function measurements we made an interesting observation. While presence of AKI was a significant predictor for eGFR decrease at discharge and last follow-up, the data provide no evidence that procedure time or other factors were significantly associated with eGFR decrease beyond 48 h. Although no significant associations were found with the other risk factors, directions of the hazards ratios conform with expectations for older age, diabetes and baseline eGFR. Lack of statistical significance may be due to the limited sample size.

\section{Accessory renal artery coverage}

Accessory renal artery coverage and other iatrogenic renal artery side branch occlusion with consecutive visible parenchymal perfusion defect on angiogram or follow-up CTA was a significant predictor for eGFR decrease in the immediate postoperative period. Any new parenchymal perfusion defect identifiable on angiogram or CTA therefore is an indicator for short-term decrease of renal function. At discharge and latest follow-up, this risk factor was still associated with increased risk of eGFR decrease $(\mathrm{HR}=1.970$ and $\mathrm{HR}=1.371$, respectively) but this association was no longer statistically significant ( $p=0.106$ and $p=0.384$, respectively). This finding is in line with the results from a non-randomized retrospective study, where no significant long-term renal deterioration was found in patients with accessory renal artery coverage during EVAR compared to a control group [26]. In the long-term, function of the focal parenchymal mass loss seems to be maintained by the remaining renal tissue. In our study, 28 cases of accessory renal artery coverage or renal artery side branch injuries occurred, of which only two cases did not show any apparent parenchymal infarction on angiographic imaging and therefore were not included in this category. Beyond registration of infarction, no attempt was made to further quantify the diameter of the occluded renal arteries and the volume of the renal tissue defect. In accordance with a Society of Vascular Surgery consensus statement on the treatment of abdominal 
Fig. 2 Mean eGFR levels with $95 \%$ confidence interval at baseline, during $48 \mathrm{~h}$ post EVAR (lowest level), at hospital discharge and at latest follow-up in patients undergoing complex EVAR. Comparison of eGFR levels in patients without acute kidney injury (coded as $0 ; n=113$ ) and with acute kidney injury (coded as $1 ; n=43$ )

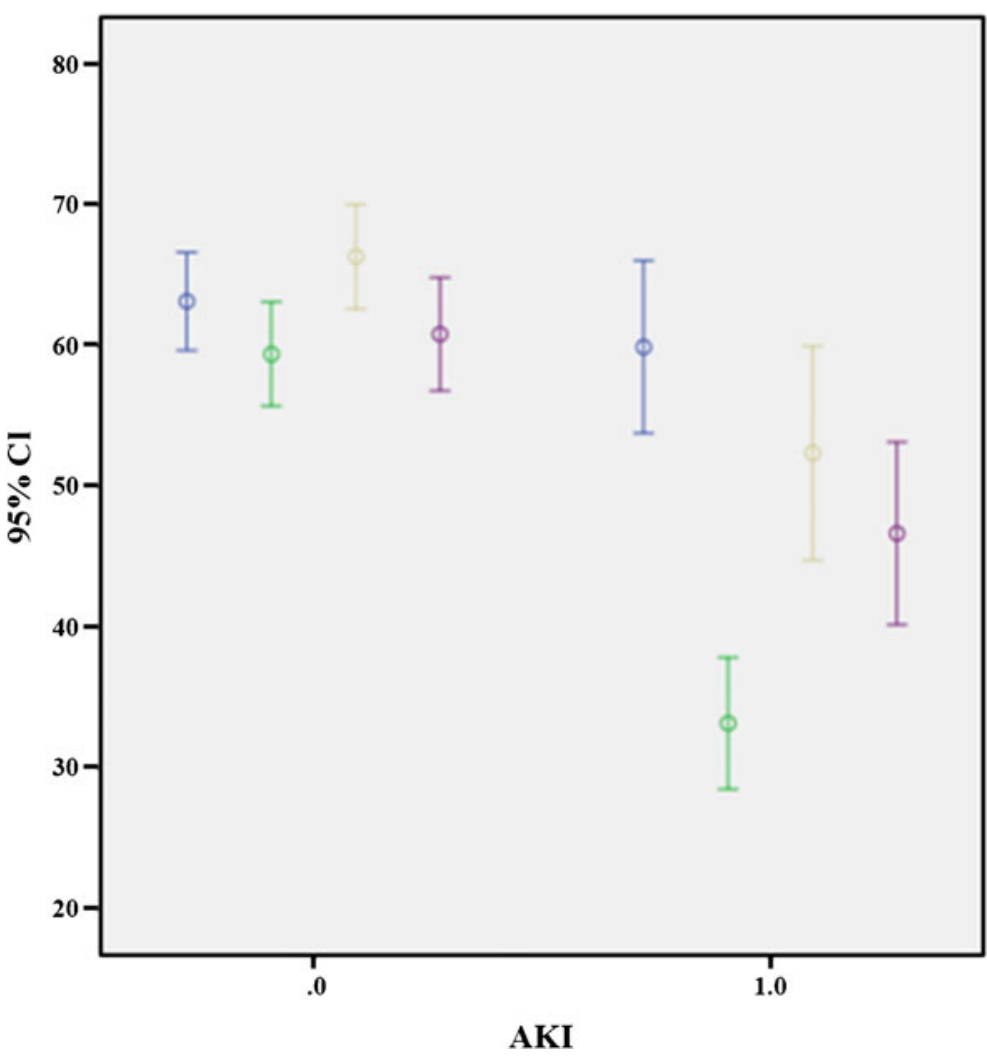

I GFR at baseline I GFR lowest during $48 \mathrm{~h}$ GFR at discharche I GFR at end of follow-up aortic aneurysms [27], at our institution only accessory arteries smaller than or equal to $3 \mathrm{~mm}$ in diameter and supporting not more than one-third of the renal parenchyma are regularly overstented. This approach seems a relatively safe method at least for the long-term renal function. For larger accessory renal arteries, we cannot infer definite conclusions from our data, and any attempt to preserve their flow (e.g. with additional fenestrations) might be favourable.

In conclusion, intra-arterial iodinated contrast volume is not an independent risk factor for development of short- or long-term renal function decrease after endovascular repair of complex aortic aneurysms. Patients who develop post-EVAR $\mathrm{AKI}$ are at significant higher risk for long-term renal function decrease.

Acknowledgments The authors want to thank Ms Stella Schreurs, MPH, for her help with data collection. The scientific guarantor of this publication is Dr. Anna Sailer MD. The authors of this manuscript declare no relationships with any companies whose products or services may be related to the subject matter of the article. The authors state that this work has not received any funding. PJ Nelemans MD $\mathrm{PhD}$ kindly provided statistical advice for this manuscript. Institutional review board approval was obtained. Written informed consent was waived by the institutional review board. No study subjects or cohorts have been previously reported. Methodology: retrospective, observational, performed at one institution.
Open Access This article is distributed under the terms of the Creative Commons Attribution-NonCommercial 4.0 International License (http:// creativecommons.org/licenses/by-nc/4.0/), which permits any noncommercial use, distribution, and reproduction in any medium, provided you give appropriate credit to the original author(s) and the source, provide a link to the Creative Commons license, and indicate if changes were made.

\section{References}

1. United Kingdom EVAR Trial Investigators, Greenhalgh RM, Brown LC, Powell JT, Thompson SG, Epstein D, Sculpher MJ (2010) Endovascular versus open repair of abdominal aortic aneurysm. N Engl J Med 362:1863-1871

2. Walsh SR, Tang TY, Sadat U, Naik J, Gaunt ME, Boyle JR et al (2008) Endovascular stenting versus open surgery for thoracic aortic disease: systematic review and meta-analysis of perioperative results. J Vasc Surg 47:1094-1098

3. Verhoeven EL, Katsargyris A, Bekkema F, Oikonomou K, Zeebregts CJ, Ritter W, Tielliu IF (2015) Ten-year experience with endovascular repair of thoracoabdominal aortic aneurysms: results from 166 consecutive patients. Eur J Vasc Endovasc Surg. doi:10. 1016/j.ejvs.2014.11.018

4. Azuma T, Yokoi Y, Yamazaki K (2013) The next generation of fenestrated endografts: results of a clinical trial to support an expanded indication for aortic arch aneurysm treatment. Eur J Cardiothorac Surg 44:e156-e163, discussion e163

5. Sailer AM, de Haan MW, Peppelenbosch AG, Jacobs MJ, Wildberger JE, Schurink GW (2014) CTA with fluoroscopy image 
fusion guidance in endovascular complex aortic aneurysm repair. Eur J Vasc Endovasc Surg 47:349-356

6. de Ruiter QM, Moll FL, van Herwaarden JA (2015) Current state in tracking and robotic navigation systems for application in endovascular aortic aneurysm repair. J Vasc Surg 61:256-264

7. Davenport MS, Cohan RH, Khalatbari S, Ellis JH (2014) The challenges in assessing contrast-induced nephropathy: where are we now? AJR Am J Roentgenol 202:784-789

8. Lee JT, Varu VN, Tran K, Dalman RL (2014) Renal function changes after snorkel/chimney repair of juxtarenal aneurysms. J Vasc Surg 60:563-570

9. Saratzis A, Sarafidis P, Melas N, Khaira H (2014) Comparison of the impact of open and endovascular abdominal aortic aneurysm repair on renal function. J Vasc Surg 60:597-603

10. Karthikesalingam A, Bahia SS, Patel SR, Azhar B, Jackson D, Cresswell L, Hinchliffe RJ, Holt PJ, Thompson MM (2015) A systematic review and meta-analysis indicates underreporting of renal dysfunction following endovascular aneurysm repair. Kidney Int 87:442-451

11. Levey AS, Coresh J, Greene T, Stevens LA, Zhang YL, Hendriksen S, Kusek JW, Van Lente F, Chronic Kidney Disease Epidemiology Collaboration (2006) Using standardized serum creatinine values in the modification of diet in renal disease study equation for estimating glomerular filtration rate. Ann Intern Med 145:247-254

12. Mehta RL, Kellum JA, Shah SV, Molitoris BA, Ronco C, Warnock DG, Levin A, Acute Kidney Injury Network (2007) Acute Kidney Injury Network: report of an initiative to improve outcomes in acute kidney injury. Crit Care 11:R31

13. McDonald RJ, McDonald JS, Bida JP, Carter RE, Fleming CJ, Misra S, Williamson EE, Kallmes DF (2013) Intravenous contrast material-induced nephropathy: causal or coincident phenomenon? Radiology 267:106-118

14. Davenport MS, Khalatbari S, Cohan RH, Dillman JR, Myles JD, Ellis JH (2013) Contrast material-induced nephrotoxicity and intravenous low-osmolality iodinated contrast material: risk stratification by using estimated glomerular filtration rate. Radiology 268:719-728

15. Davenport MS, Khalatbari S, Cohan RH, Ellis JH (2013) Contrast medium-induced nephrotoxicity risk assessment in adult inpatients: a comparison of serum creatinine level- and estimated glomerular filtration rate-based screening methods. Radiology 269:92-100

16. Ehrmann S, Badin J, Savath L, Pajot O, Garot D, Pham T, Capdevila X, Perrotin D, Lakhal K (2013) Acute kidney injury in the critically ill: is iodinated contrast medium really harmful? Crit Care Med 41:1017-1026
17. Waikar SS, Liu KD, Chertow GM (2008) Diagnosis, epidemiology and outcomes of acute kidney injury. Clin J Am Soc Nephrol 3: 844-861

18. Stacul F, van der Molen AJ, Reimer P, Webb JA, Thomsen HS, Morcos SK, Almén T, Aspelin P, Bellin MF, Clement O, HeinzPeer G, Contrast Media Safety Committee of European Society of Urogenital Radiology (ESUR) (2011) Contrast induced nephropathy: updated ESUR Contrast Media Safety Committee guidelines. Eur Radiol 21:2527-2541

19. American College of Radiology Committee on Drugs and Contrast Media (2015) Manual on contrast media, 10th edn. ACR, Reston. http://www.acr.org/ /media/ACR/Documents/PDF/QualitySafety/ Resources/Contrast\%20Manual/2015_Contrast_Media.pdf. Accessed 20 September 2015

20. Tepel M, Aspelin P, Lameire N (2006) Contrast-induced nephropathy: a clinical and evidence-based approach. Circulation 113: 1799-1806

21. Liu YH, Liu Y, Tan N, Chen JY, Zhou YL, Luo JF, Yu DQ, Li LW, Li HL, Ye P, Ran P (2015) Contrast-induced nephropathy following chronic total occlusion percutaneous coronary intervention in patients with chronic kidney disease. Eur Radiol 25:2274-2281

22. Baumgarten DA, Ellis JH (2008) Contrast-induced nephropathy: contrast material not required? AJR Am J Roentgenol 191:383-386

23. Hayakawa K, Tanikake M, Kirishima T, Yoshinami N, Shintani H, Yamamoto E, Morimoto T (2014) The incidence of contrastinduced nephropathy (CIN) following transarterial chemoembolisation (TACE) in patients with hepatocellular carcinoma (HCC). Eur Radiol 24:1105-1111

24. Stratta P, Izzo C, Canavese C, Quaglia M (2013) Letter to the Editor re: Are intravenous injections of contrast media really less nephrotoxic than intra-arterial injections? Eur Radiol 23:1260-1263

25. Katzberg RW, Newhouse JH (2010) Intravenous contrast mediuminduced nephrotoxicity: is the medical risk really as great as we have come to believe? Radiology 256:21-28

26. Greenberg JI, Dorsey C, Dalman RL, Lee JT, Harris EJ, Hernandez-Boussard T, Mell MW (2012) Long-term results after accessory renal artery coverage during endovascular aortic aneurysm repair. J Vasc Surg 56:291-296, discussion 296-297

27. Chaikof EL, Brewster DC, Dalman RL, Makaroun MS, Illig KA, Sicard GA, Timaran CH, Upchurch GR Jr, Veith FJ (2009) SVS practice guidelines for the care of patients with an abdominal aortic aneurysm: executive summary. J Vasc Surg 50:880-896 